\title{
GRANULOMA EOSINOFILICO DE LOS HUESOS
}

\author{
Por los Dies, AGUSTIN INOSTROSA. RENE ARTIGAS, JULIO ESPINUZA \\ y GUILLERMO VALENZUELA \\ Sarvitios de Ciragia lnfantil, Ontopedia Y Trantmatología, Instituto de Anatomia-Patológica \\ I Servício de Radiologia, Hospital M. Arriarán.
}

Desde que en 1940 Lichtenstein y Jaffe describieron casi simultáneamente con Otani y Ehrlich, en EE. UU. de Norte América, la enfermedad que hoy nos preocupa, denominándola los primeros "Granuloma eosinofílico" y los segundos "Granuloma solitario", han pasado ya de la centena los casos publicados en la literatura médica mundial. Sin embargo, antes de la fecha anotada, otros autores, en diversos países, habían hecho notar su existencia, aunque rotulándola con un nombre distinto. Es así cómo Finzi, en 1929, la llamó "Mieloma con prevalencia de células eosinófilas"; Mignon solamente "Granuloma"; Mancini, en 1935, "Mieloma solitario" y Schairer, en 1938, "Osteomielitis con eosinófilos". Aunque en la actualidad ya está consagrada por el uso Ja denominación de Granuloma eosinófilo de los huesos, la diversa nomenclatura utilizada antes de 1940 habla de las dificultades diagnósticas en sus aspectos clínico e histopatológico y hasta hoy día persisten dudas respecto de su patogenia, habiéndose liegado a afirmar de parte de numerosos autores que más que una nueva entidad clínica $y$ anatómica independiente, se trata sólo đe una modalidad o variante de un mismo cuadro patológico, en que se incluyen asimismo la Enfermedad de Hand-Schüller-Christian y Létterer-siwe.

Entre nosotros, el Dr. José Bengoa, del Hospital "Deformes" de Valparaíso, dió a conocer en un documentado trabajo publicado en el Boletín del Hospital de Viña del Mar, en 1946, el primer caso de Granuloma eosinófilo de los huesos que se diagnosticara en nuestro país. Es nuestro propósito contribuir a la casuística nacional de esta afección con cuatro nuevos casos observados desde 1948 hasta el presente año en el Servicio de Cirugia dei Hospital Arriarán. Pero antes de referirnos explicitamente a los enfermitos, motivo de esta presentación, permítasenos bosquejar sucintamente la patología de esta poco común y discutida enfermedad.

Frecuencia y localización. - Clásicamente se la ha descrito en la niñez y adolescencia, pero ya ha comenzado a encontrarse en adultos. Así, por ejemplo, Latienda, Reggi y Garré han publicado el caso de un enfermo de 58 años afecto de Granuloma eosinófilo múltiple de los huesos; Blumenfeld, el de un hombre de 49 años; Parkinson, otro de 56 años y Green y Farber dicen haber estudiado también varios casos en adultos. Según la mayoría de los autores, predomina en el sexo masculino.

Asienta con predilección en los huesos planos, principalmente del cráneo, cara, costilla y pelvis, encontrándose también en los huesos largos, tales como el fémur y húmero. Contrariamente a lo supueste por Lichtenstein y Jaffe, no hacen excepción a este respecto los huesos metacarpianos, metatarsianos y falanges. Según los casos publicados, en realidad cualquier hueso puede ser afectado por 
do la lesión es múltiple, forma que al parecer es más frecuente que la solitaria. En una serie de 9 enfermos relatados por Green y Farber, 5 de los cuales tenían lesiones múltiples, el término medio de las lesiones fué đe 16 en cada caso, con un máximo de 45 en un enfermo. En los huesos largos, la ubicación exacta es variable, pudiendo corresponder a la diáfisis, aunque con mayor frecuencia cerca de las epifisis.

Etiología y patogenia. - La etiología es hasta hoy día desconocida. Algunos insinúan la posibilidad de una infección leve, pero la investigación más cuidadosa de gérmenes ha sido negativa. También se ha supuesto se trata de un granuloma a virus (Lichtenstein $\bar{y}$ Jaffe); otros aseguran cierto papel al traumatismo (Shairer, Otani y Ehrlich) y hay quienes sostienen una etiologia alérgica (Irascano González-Surberger). Desde el punto de vista de la patogenia, numerosos autores afirman que el Granuloma eosinófilo es una forma localizada de una retículo-endoteliosis, de la cual también forman parte la enfermedad de HandSchüller-Christian $y$ de Létterer-Siwe. Abonan esta concepción patogénica el hallazgo de estados de transición entre el granuioma eosinófilo solitario o múltiple, libre de lípidos, el granuloma con fagocitosis lipoídica incipiente, hasta llegar al tejido xantomatoso típico, o casos de localizaciones múltiples con diabetes insípida o finalmente pacientes con enfermedad de Hand-Schüller-Christian y granulomas eosinófilos múltiples. Por todo esto, Farbe, Jaffe y Lichtenstein, Curtis y Cawley, y muchos otros, consideran que la enfermedad de Létterer-Siwe, la Hand-Schüller-Christian y el Granuloma eosinófilo del hueso son manifestaciones diversas de un trastorno básico idéntico y opinan que el Granuloma eosinófilo representa el tipo más leve y menos grave. Mallory, que participa plenamente de este concepto patogénico, dice textualmente: "existe fuerte evidencia sugestiva de que estos diferentes sindromas representan una misma entidad, aunque la prue- ba de esta identidad debe esperar el descubrimiento de la etiología".

Sintomatología. - La sintomatologia subjetiva puede ser nula o manifestarse por sensación de molestia o dolor en la zona afectada. Si asienta en una articulación puede haber claudicación. El examen físico en casos que afecta el cráneo, revela tumoración circunscrita de tamaño variable, remitente y generalmente indolora. En los huesos largos se encuentra tumefacción localizada y edema. Aun en enfermos con Granuloma eosinófilo múltiple son raros los signos de enfermedad general y no son escasos aquellos enfermos que revelan su enfermedad por una fractura patológica o por una radiografía tomada con otro objetivo.

Radiográficamente, las zonas destruídas, mono o poliquísticas, no tienen nada de característico: son de límites precisos, con sus bordes constituídos por hueso de aspecto normal. Sólo cuando existen grandes destrucciones óseas suele observarse reacción periostal de hueso neoformado. El aspecto de estas lesiones es parecido en el Granuloma eosinófilo óseo, en la enfermedad de Hand-Schüller-Christian y en la enfermedad de Létterer-Siwe.

$\mathrm{El}$ estudio hematológico no revela nada especifico: puede haber leucocitosis moderada con neutrofilia o eosinofilia, que varía del 3 al $10 \%$. El calcio, fósforo, fosfatasa, colesterol, proteína total y relación albúmina-globulina son normales.

Anatomía Patológica. - Macroscópicamente, la cavidad ósea se observa ocupada por un tejido rojizo o amarillento, gelatinoso y con focos de aspecto necrótico. El cuadro microscópico de este tejido varia, según Green y Farber, de acuerdo con la duración del proceso, el grado de destrucción ósea y la cuantía de la reparación, pero en todo caso se trata de una lesión de tipo granulomatoso. En un estado precoz se observan numerosos eosinófilos y grandes fagocitos mononucleados (histiocitos). Aquéllos son leucocitos maduros y frecuentemente mielocitos, no todos los cuales son eosinófilos, 
de donde se deriva el falso diagnóstico de mieloma mielocítico. Los eosinófilos forman grandes acúmulos que colorean de rojo el campo o se distribuyen difusamente. Se encuentran, además, en número variable: células plasmáticas, linfocitos y pequeños focos de polinucleares no asociados a infección bacteriana ni abscesos. Los fagocitos mononucleados varian considerablemente de tamaño; su citoplasma es granuloso, vacuolar o esponjoso, conteniendo a menudo fragmentos de eosinófilos o neutrófilos, partículas de hueso o restos irreconocibles; el núcleo es ovalado o en herradura, único o múltiple. En un estado tardío del proceso, los eosinófilos disminuyen en cantidad, predominando los grandes mononucleados, muchos de ellos vacuolares y evidente proliferación fibroblástica. Más avanzado aún el proceso, los mononucleados fagocitarios muestran vacuolización completa (lipófagos), dando el aspecto típico de las células espumosas del xantoma, a lo cual sigue un lento reemplazo del tejido granulomatoso por tejido conjuntivo que a su turno se transforma en hueso. Desde los estados precoces hasta la constitución de lipófagos, el Escarlata $R$ revela lípidos coloreables. Los vasos sanguíneos de neoformación, que son numerosos, no presentan lesiones inflamatorias (nodular o perivascular) ni proliferación de sus túnicas.

Diagnóstico. - Todos los autores están de acuerdo en que, aunque el Granuloma eosinófilo puede sospecharse clínica y radiográficamente, el diagnóstico positivo sólo puede hacerse en el examen histopatológico.

Clinicamente, es preciso hacer diagnóstico diferencial con todas las lesiones destructivas de los huesos, simples o múltiples. Si la lesión es solitaria, debe diferenciársela de la osteomielitis, tuberculosis, sífilis, quiste solitario del hueso, tumor de células gigantes y tumor de Ewing. Cuando es múltiple hay que considerar: el mieloma múltiple, metástasis de neuroblastoma o linfosarco- ma y osteítis fibrosa quística generalizada. En cualquier caso, hay que tomar en cuenta que una lesión ósea puede ser una manifestación monosintomática de la enfermedad de Hand-Schüller-Christian, que aun puede curar sin llegar a la forma generalizada o adquirir en el futuro la forma plurifocal con sus síntomas típicos.

Pronóstico y tratamiento. - La experiencia de los autores consultados habla en favor de un pronóstico bueno, especialmente en las lesiones solitarias. En casos de lesiones múltiples, el pronósti$c o$, naturalmente, tiene que ser reservado, ya que debe sospecharse o tenerse la posibilidad de un compromiso sistémico o de lesiones viscerales que signifiquen el desarrollo de alguna retículoendoteliosis, principalmente la enfermedad de Hand-Schiller-Christian. También hay que hacer algunas reservas en lo que se refiere a la localización del proceso y la probable complicación de fractura, casos éstos que no son raros en la casuístíca publicada y que no sólo involucran un trastorno funcional pasajero, si no pueden posteriormente dar lugar a desviaciones del miembro. Platt y Eisemberg, Lihtenstein, Ponseti y varios otros autores, han podido comprobar la curación espontánea de algunos casos o de algunos focos de enfermos afectos de Granuloma eosinófilo solitario o múltiple. Por lo demás, cualquiera que sea el tratamiento: raspaje, roentgenterapia o radiumterapia, sola o combinada, da buenos resultados, lo que indica la gran tendencia que tiene este proceso a la curación. Como regla general, dice Ponseti, que mientras más viejo es el enfermo, más favorable es el pronóstico. Este mismo autor agrega, que en su serie de 8 casos no vió reciđiivas después de la intervención quirúrgica 0 roentgenterapia $y$ que aun en formas particularmente malignas, resistentes al tratamiento y que recurren produciendo gran destrucción ósea, el pronóstico es bueno. 
Nuestros casos.

CAso No 1, - S. G. R. 13 años. Ingresa XI-48.

Vive en el campo. Antecedentes hereditarlos y personales sin importancia. Enfermedad actual: A raíz de un pequeño traumatismo, dos meses antes de su ingreso nota aumento de volumen blando en la reglón parletal izquierda, poco doloroso, que se reabsorbe espontáneamente casi en su totalldad. Quince dias antes de su Ingreso recibe una fedrada de poca intensidad en esti misma zona, apareciendo inmediatamente gran aumento de volumen blando, poco doloroso; se diagnostica hematoma parietal y se punciona, extrayendo 60 ce de sangre obscura liqui- da. Evolución post-operatoria excelente, sin ninguna complicación. Clcatrización p. p. de la herdda operatoria.

Como este proceso siseo destructivo no concordara con ninguna entidad nosológlca conocida por nosotros hasta ese momento, le practicamos a nuestro enfermo todos los exámenes que pudieran darnos alguna luz: radloscopia de tórax, Mantoux, sedimentaclon, orina, Kahn, Wassermann, uremia, gllcemia, colesterol, etc, todos ellos fueron negativos; en el hemograma sólo estaba fuera de lo normal una eosinofilia de 13 , que atribuimos a una probable parasitosis intestinal, siendo, por lo demás, los exámenes seriados de deposiclones tamblén negativos.

Ed informe anátomo-patológico del raspado óseo nos dió la clave diagnóstica. Dice así:

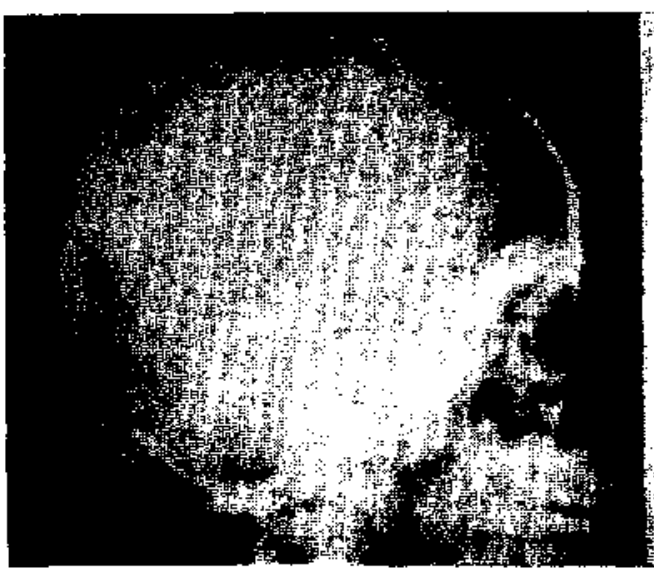

Ràdiografia $\mathrm{N}^{2} \mathrm{~L}$

Caso N" 1. S. G. Imagen osteolitica redondeada, sin reacsión de yecindad, parietsl izquierda.

da. Se coloca vendaje compresivo; dos dias después se ha reproducldo, nueva punción, encontrando esta vez un rodete duro semicircular, que hace sospechar un hundimiento oseo. La radiografia de control revela una imagen osteolítica de contornas redondeados de más o menos $3 \mathrm{~cm}$ de diámetro; pese a este resultado radiográfico se intervlene con el diagnóstico probable de hundimiento parietal, encontrando en la intervención gran cantidad de sangre en vías de organizaclón y la lámina externa completamente destruida, al igual que el diploe y la lámina interna, de un aspecto, si se me permite la expresión. como apolillada; hacla la perifería de esta zona destructiva gran parte deI hueso revela signos evidentes de osteolisis, pero de menor intensidad. Se procede \& un raspaje minucloso con cuchartlla y cierre de la heri-

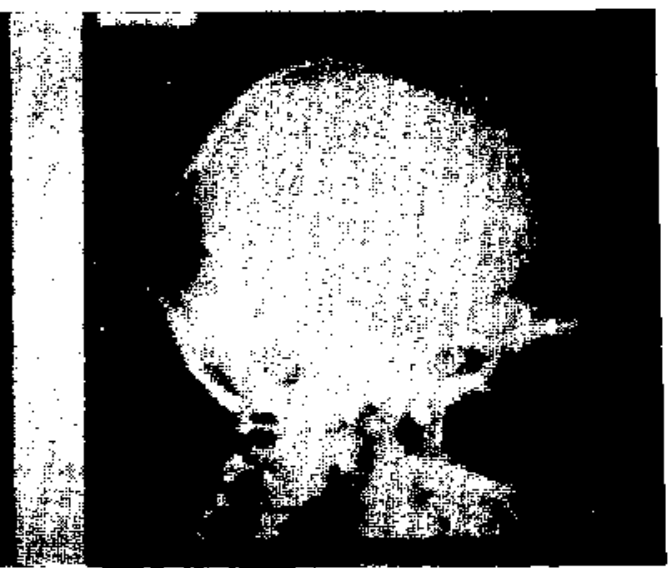

Radiografia $N^{\circ} 2$

Caso N" 1, S. G. Tres años y medio desprues de la intervención no se aprzcian vestigios de ?a lesión primitiva.

Biopsia N" 115-116, 21 VII-48, El examen microscópico revela un tejido granulatorio rico en capilares neoformados e infiltrado por abundantes células de clase diferente, que en orden de frecuencia son las siguientes: histiocitos, polinucleares predominantemente eosinóftlos y Infocitos. Los histiocitos se observan en general conglomerados en focos, son de tamaño variable y a veces con varios núcleos, hasta seis; su citoplasma es claro, abundante $y$ en ocasiones contiene pigmento sanguineo. Los polinucleares siembran difusamente el tefldo examinado y en ocasiones son $\tan$ abundantes que colorean de rojo el campo, están distribuídos difusamente, aunque se encuentran de preferencia en pequeños focos en la perifería de las trocitos examinados, donde aparece una membrana ftbrosa que está sembrada de acúmulos he- 
mosiderinicos. Vasos sanguineos' hiperhémicos y algunos con discreta hiperplasia de sus endotelios.

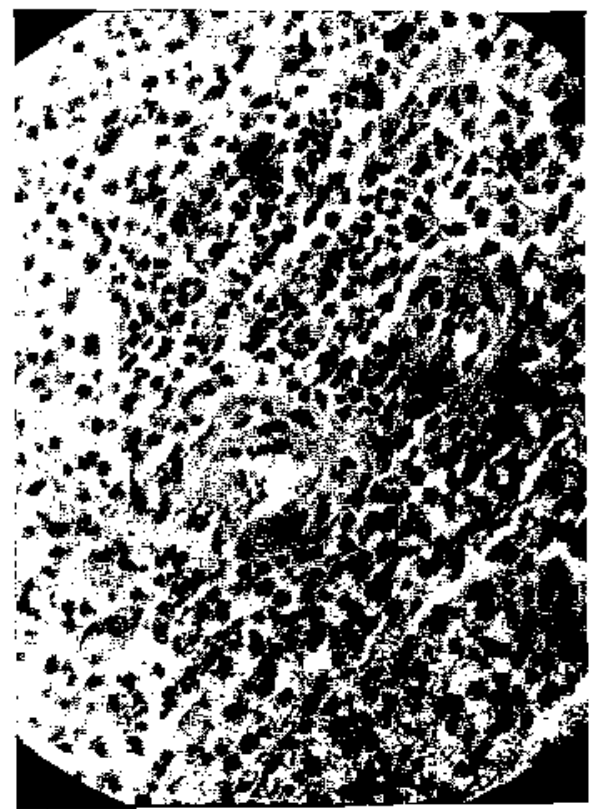

Microfotografía $\mathrm{N}^{\mathrm{B}} 1$

Caso $N^{4}$ 1. X 90. Hematoxilina-Eosina. Tejido granulomatoso rico en polinueleares cosinófilos e hisciocitos. Al centro, los capilares con acentuada fibrosis de sus paredés y proliferación de sưs endocelias.

Los controles posteriores han revelado regeneración rápida de su lesión ósea, sin provocar nuevas molestias. La última radiografía tomada tres años y medio después de la operación no revela rastras de su lesión prímitiva. Actualmente está trabajando en perfectas condiciones en una viña cerca de santiago.

Tímpo de control: 3 años 8 meses. Resultado: sano.

CAsSo $\mathrm{N}^{*}$ 2. - Marcelo C. J. 6 añas. $\mathrm{Ob-}$ serv. N" 75862, Ingresa IX-50.

Antecedentes negativos. Una semana antes de su ingreso se cae en la calle, queda con discreta claudicación del miembro inferior izquierdo, pero puede deambular sin grandes dolores; como después de 8 dias sus molestias se mantienen, consulta en el Servicio, pueliéndose apreciar un enfermo con buen estado general, claudicación discreta, movilidad completa activa y pasiva de la cadera, pero algo dolorosa; longitud de ambos miembros iguales; no se aprecian ganglios infartados ni atrofia muscular. La radiografia reveló intenso proceso destructivo del cueIIo del fémur, con compromiso de la cort1cal, cerca del trocänter mayor. Bajo anestesia general, biopsia ósea por punctión, que da salida casi exclusivalmente a sangre, seguida de yeso pelvipedio. Todos los exámenes de rutina y otros fueron negativos.

Informe de Blopsia $\mathrm{N}^{\circ}$ 1:57, 28-IX-50, informaba asf: Muestra muy pequeña, que microscópicamente se presenta constituída por tejido fibro-muscular $\mathrm{g}$ pequeños trocitos de cartilago hialino. En los bordes de la muestra se aprecla un discreto infiltrado inflamatorlo, a base de linfocitos y polinusleares

Diagnóstico: Ligera inflarnación sub-aguda.

Das meses más tarde se rehospitaliza. Retirado el yeso se aprecia movilidad de la cadera discretamente limitada, en especial para la flexión, discreta atroffa muscular y es-

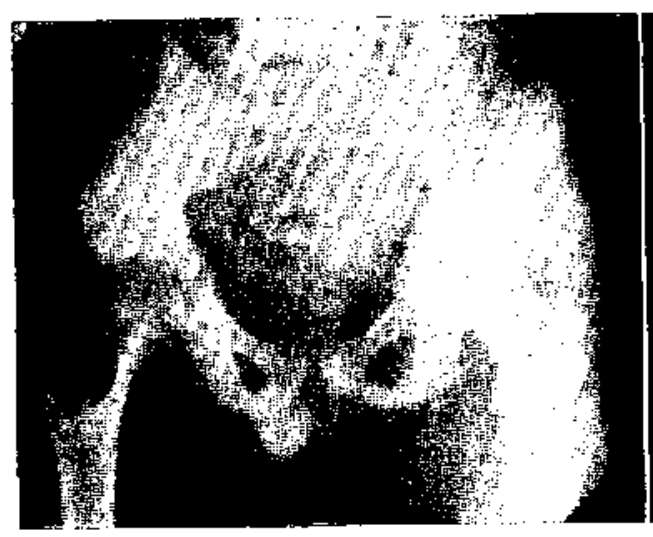

Radiogenfía N* 3

Caso $N^{\circ}$ 2. M. C. Gran imagen osteolitica del cuello del fémur (tomada 2 meses después de la biopsia ósea por punción).

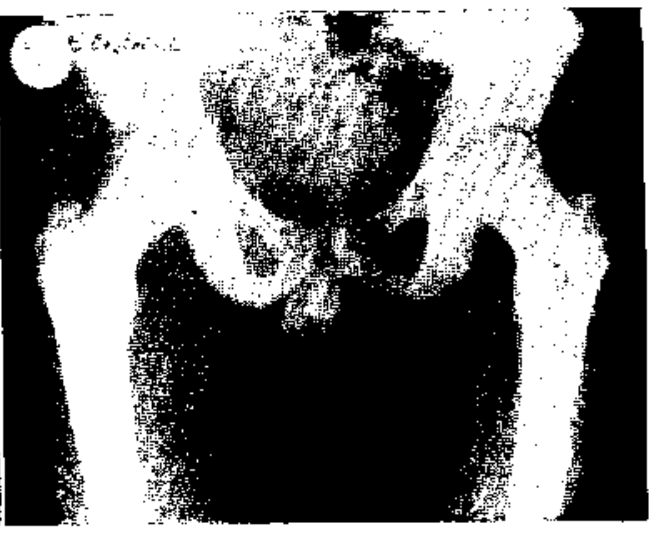

Radiografia $N^{\circ} 4$

Cazeo N4 2. M. C. Repatarión ósea complata al año y medio de la intervención. (Raspaje de la cavidad seguida de injerto óseol. 
tado general espléndido, mejor que en su primera hospitalización, pero llama profundamente la atención que el control radlográfico contrasta seriamente, por cuanto la lesión destructiva del cuello del fémur ha progresado en una forma evidentísima, tanto que se plantea la posibilidad de un sarcoma, por la rípida evolución.

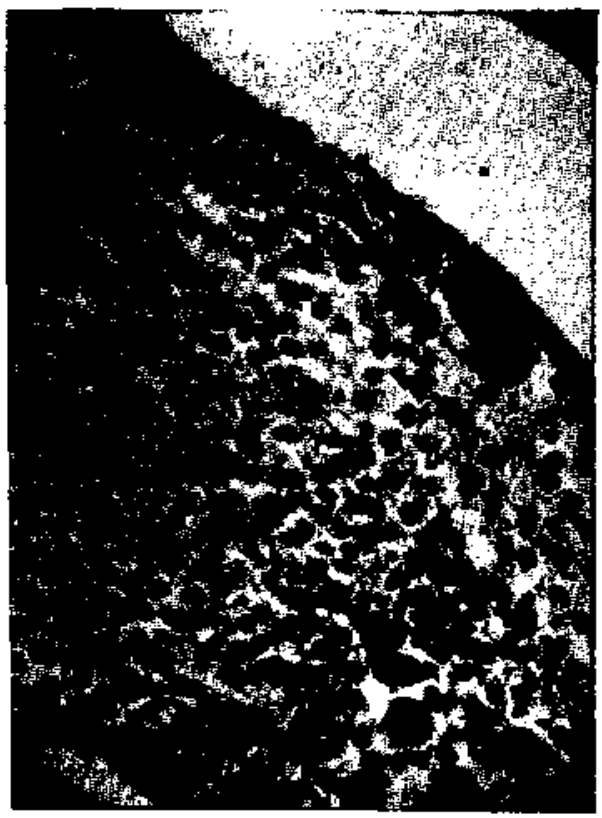

Microfotografía $\mathrm{N}^{\circ} 2$

Caso $N^{\prime \prime}$ 2. X 90. Hematoxilina-Eosina. Focos de células histiocicarias "en cultivo puro". A la derecha y arriba se ve una câlula gigante con 7 núcleos.

En estas condiclones se procede a intervenir. Se aborda el cuello del fémur, encontrando una cayidad amplia, que se continúa con tejido fungoso, encefaloídeo; dentro de ella hay una substancia gelatinosa flúida de color rojo-amarillento. Raspaje prolijo de la cavldad, encontrándose hueso sano a poea profundidad. Cierre por planos, penicilina local $y$ yeso pelvipedio. Evolución post-operatorla excelente. El Informe anátomo-patológico en esta segunda oportunidad fué el siguiente: Biopsia $\mathbf{N}^{*}$ 207-208, 27-XI-50. Varíos pequeños trozos de tejido que microscópicamente se presentan formados por tejido granulatorio muy rico en capilares ô neoformación y numerosas células mononucleadas: histiocltos que son muy abundantes y linfocitos en menor cantidad, encontrándose, además, numerosos easinófilos mono y polinucleares distribuidos difusamente $\mathrm{y}$ que en ocasiones se acumulan en grandes cantidades. Los histiocitos son de tamaño y forma variables, se reparten difusamente, pero sue- len conglomerarse en focos que por su abundante citoplasma claro hacen contraste con el resto del tejido. Se observan tambtén células gigantes mono $\mathrm{y}$ polinucleares, hasta con veinticinco núcleos, con aspecto de mieloplaxas, células de Langhans o de Stenberg. Vasos sanguineas can proliferación de sus endotellas. Intersticio con algunos focas necrćticos hemorrágleos y escazo pigmento sanguíneo fagocitado por macrófagos. Escasos y pequeños focos calcificados y restos de trabéculas óseas.

Diagnóstico: Granuloma eosinofilico.

Se envia al Instituto del Rađium, donde le hicieron cuatro aplicaciones de Roentgenterapia profunda.

Los controles posterionmente revelaron reparación csea rápida e integral; el enfermo no acusa molestias de ninguna especie, hace su vida normal y el último control radiográfico thecho a principios de este año revela re. paración ósea completa.

Tiempo de control: $1 \frac{1 / 2}{1 / 2}$ año. Resultado: sano.

CAso $\mathbf{N}^{n} 3$, - Sergio V. A. 4 añas, $O_{\text {- }}$ serv. $N^{\circ} 77742$. Ingresa VII-51.

Enfermedad actual: UJ mes antes de su ingreso resibe un puntapié en la región de

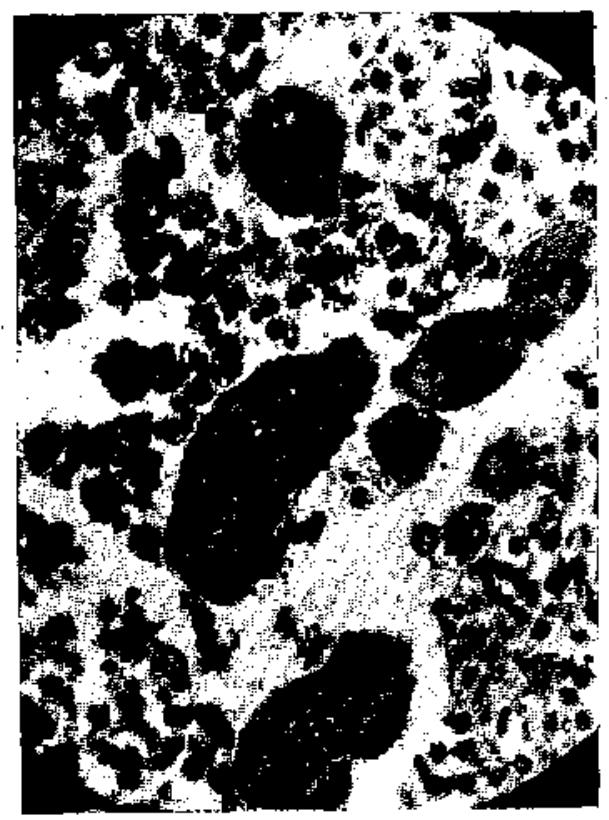

Microfotografía $N^{\circ} 3$

Caso N: 3. X 90. Hematoxilina-Eosina. Numetosas células gigantes, la mayor. central, con 37 núclens. que incluyen restos leucocilatios. Entre ellas y a su alrededor, histiocitos de tamaño variable y algunos eosinófilos, 
la cadera derecha, deambula con intenso dolor, por lo que debe guardar reposo en cama, a pesar de lo cual sus molestias no ceden. por cuyo motivo consulta en el servicio. El examen clínico reveló dolor espontáneo a nivel de la cadera derecha, escollosis de concavidad derecha por gran contractura de los espinales, rodilla derecha en recurvatura; al deambular claudicación intensa y acentuada lordosis lumbar; en decúbito dorsal desaparece toda esta sintomatología, persistiendo sólo el dolor; movilidad completa e indolora de la cadera del lado afectado. Se practlcan todos las exámenes de rigor, incluso la radiogratia, siendo ellos negativos, a excepctón del hemograma, que revelo una intersa leucoc1tosis, 43,300 y una sedimentación de $12-48 \mathrm{~mm}$.

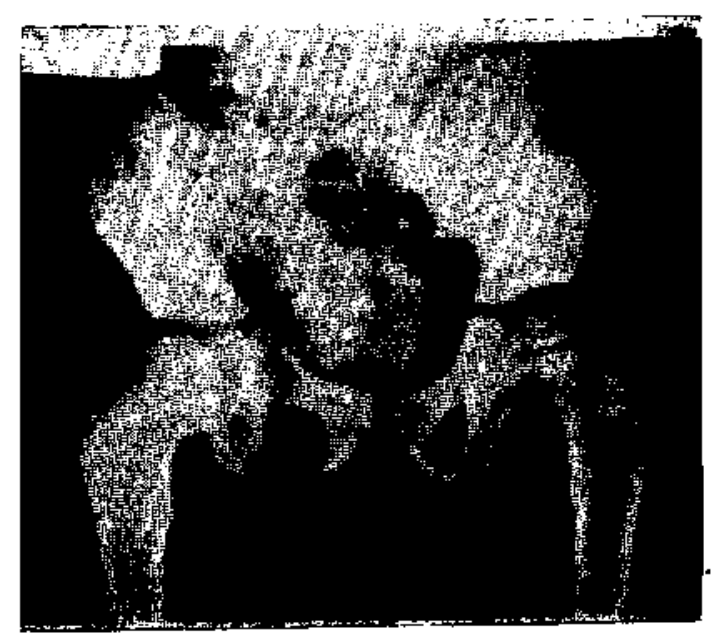

Radiografia No 5

Caso Ne 3. V. A. Esclerosis de la hemipelvis derecha, lesión primitiva ba desaparecido. (Tomada después de 12 sesiones de rádinmterspial.

Se continúa el estudto hematológico completo, con mielogramas, hemogramas seriados, reacción de Paul Bunnel, etc., que no da mayores luces, y que por el contrario, en el plazo de un mes todo ha vuelto a la normalidad, pero la sintomatologia primitiva del enfermo continúa igtual, apareciendo aumento de volumen a nivel del ala llíaca derecha, sin caracteres inflamatorios y muy poco doIorosa. Nueva radiografia en esta oportunidad, previo lavado intestínal, reveló carie ósea del ala ilíaca, sospechosa de asteomielitis. Preparado el enfermo se interviene: abordado el hueso lííaco se encuentra una zona destructiva del tamaño de una moneda de un peso, cavidad llena de tejído fungoso, de color rojo-amarillento, rodeado de una zona ósea blanda, delgada y bastante extensa. Raspaje a cucharilla y drenaje in situ para irri- gaciones continuas con penicilina. Cierre de la herida. Evolución post-operatorla excelente, sin complicaciones y cicatrización p. p. de la herida operatoria.

Informe anátomo-patológico, Biopsia, $\mathbf{N}^{2} 231$, 7-VII-51: Pequeños trozos de tejido que microscopicamente se encuentran formados por tejido granulatorio muy rico en capliares $y$ numerosas células retículo-endoteliales distribuidas difusamente. Estas células son de tamaño variable con citoplasma abundante y claro y núcleos con finos gránulos croniáticos. Entre ellas se observan numerosos eosinófilos y linfocitos; estos últimos conglomerados en ocasiones en pequeños nódulos. Se observan, además, células gigantes con uno 0 varios núcleos dispuestos en círculo en la perifería de las células $o$ en el centro de ellas. AIgunas de estas células contienen en su interlor fino pigmento hemosiderinico y restos nucleares. Vasos con acentuada proliferación de sus endotelias y en ocasiones con sus delgadas paredes hialinizadas.

Diagnóstico: Granuloma eosinofilico.

Posteriormente el enfermo es enviado al Instituto del Radium, donde le hacen doce aplicaciones de roentgenoterapia profunda. El úlimo control efectuado el 15-III-52 revela lesión ósea desaparecida, pero se aprecia gran deformactón y esclerosis del hueso lliaco, provocada por las radiaciones. Clínicamente en perfectas condiciones.

Tiempo de control: 9 meses, Resultado: sano.

CAso N" 4. - Juan S. B. 6 años, Observ. N" \$7044. Ingresa I-52.

Antecedentes: Siempre sano, controlado periódicamente en un servicio médico de las F'uerzas Armadas.

Enfermedad actual: Hace alrededor de un mes aparece aumento de volumen $\sin$ causa aparente, frontal izquierdo, indoloro, de crecimlento lento, pero progresivo. Al examen se aprecla aumento de volumen del tamaño de una nuez, blando, no fluctuante, de bordes redondeados, lisos, superficie uniforme, no desplazable en la profundidad, ni adherido a los flanos superficiales, indoloro.

En el acto operatorio se apresia una cápsula quistica, intimamente adherida al hueso, que al desprenderla se rompe, dando salida a sangre espesa y obscura. Hueso frontal cariado hasta la tabla interna y sin vestigios de la externa ni de diplos en una extensión de unos $3 \mathrm{~cm}$. Raspaje a cucharilla y cierre de la herida.

Evolución post-operatoria excelente, sin complicaciones. Cicatrización $p$. $p$, de la herida.

Informe anátomo-patológico, Biopsia $\mathrm{N}^{\circ} 7$, 18-I-52: Trozo de tejido blanquecino que mide $1.5 \times 1.2 \mathrm{~cm}$. Microscópicamente está for- 
mado por tejido fibroso, en una de cuyas caras revela un abundante tejido granulomatoso, rico en vasos sanguíneos y células bistiocitarias, que en algunas zonas constituyen grupos ouros de dichas células, sólo acompaז̃adas por algunos elementos gigantes con varios núcleas, hasta 37 , que se distribuyen alrededor del protoplasma o en el centro de él. Existe, además, regular cantidad de eosinófilos, que en general se cistribuyen difusamente y linfocitos dispuestos en gran parte en pequeños nódulos. Vasas sanguíneos

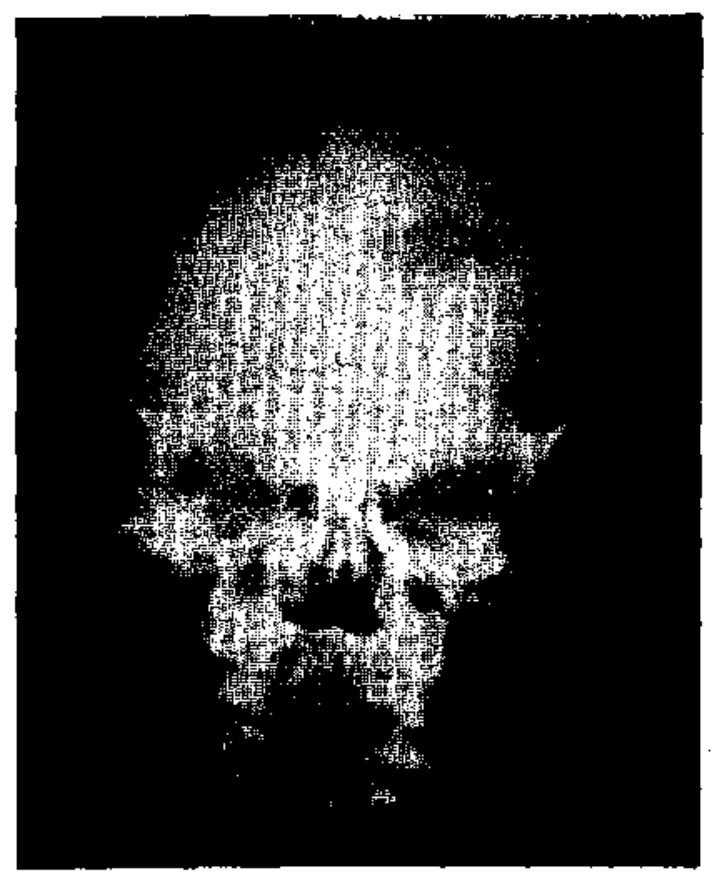

$$
\begin{gathered}
\text { Radiografia No } 6 \\
\text { Caso No 4. J. S. Imagen osteolitica } \\
\text { itregrat del frontal izquierdo. }
\end{gathered}
$$

hiperhémicos y algunos con acentuada hiperplasia de sus endotellas. Focos hemorrágicos antiguos $y$ recientes. Abundante plgmento hemosiderinico libre y fagocitado.

Diagnóstico: Granuloma easinofílico.

Actualmente enfermo en tratamiento; se aprecia en los controles reacción ósea intensa.

Tiempo de control: 3 meses.

Resultado: en tratamiento. Mejor.

\section{Comentario.}

Nuestros cuatro casos corresponden a niños cuya edad varía entre los 4 y 13 años, todos del sexo masculino. En los tres primeros se obturo un claro antece- dente traumático, que precedió a la sintomatología, por la cual consultaron en el Hospital. En dos de ellos, la lestón estaba ubicada en el cráneo: región parietal izquierda y frontal izquierda, respectivamente (casos 1 y 4) y en los restantes en el cuello femoral izquierdo $y$ ala ilíaca derecha, respectivamente (casos 2 y 3). En estos últimos, en que la enfermedad comprometía un miembro inferior, se observó una claudicación más a menos acentuada y dolor espontáneo o provocado por la movilización pasiva del miembro. En aquellos casos

( 1 y 4) en que se afectó un hueso craneal, existía un aumento de volumen circunscrito, blando, no fluctuante, de bordes redondeados y lisos e indoloro.

El hemograma practicado en dos de ellos (casos 1 y 3 ) reveló en el primero eosinofilia de $13 \%$ y en el segundo, intensa ieucocitosis de 43,300 sin eosinofilia. Esta leucocitosis cedió rápidamente en el plazo de un mes y su etiología no fué aclarada.

En todos nuestros casos el estudio radiológico demostró lestones unifocales osteolitıcas, redondeadas $u$ ovales, netamente demarcadas del tejido normal adyacente $\mathrm{y}$ sin reacción esclerótica a su alrededor. En los casos del cróneo (1 y 4), Ia lesión destruía tanto la lámina exterma como el díploe, en una extensión de $3 \mathrm{~cm}$ de diámetro más o menos, a cuyo nivel había abundante materia hemorrágica espesa, con aspecto de coágulos sanguíneos en organización. En el caso $1^{\circ}$, la intervención demostró que la osteolisis comprometía también Ia periferia de la cavidad radiológicamente evidenciada. En los otros dos casos, la operación descubrió idénticas lesiones destructivas y abundante tejido fungoso, en las cavidades neoformadas, rodeadas, como en los casos anteriores, de hueso de aspecto normal.

El estudio histopatológico de todos ios casos revel6 en ellos el típico tejido granulomatoso, rico en polinucleares eosinófilos e histiocitos, ya sembrado difusamente el tejido, como sucede en general con los eosinófilos y constituyendo 
focos circunscritos, como fué corriente hallazgo, respecto de los histiocitos. A éstos se agregaban en cantidad variable, linfocitos, generalmente en forma de nódulos, células plasmáticas distribuídas difusamente y acúmulos hemosiderínicos. Sobresaliendo por su tamaño, aparecían células gigantes histiocitarias, hasta con 37 núcleos ordenados caprichosamente, simulando mieloplaxas, células de Langhans o de Stenberg y con inclusiones diversas, constituídas por restos de polinucleares, núcleos fragmentados y pigmento sanguíneo. El tejido fibroso adulto y fibroblastos sólo se ob- de la cavidad, seguido en dos de ellos (casos 2 y 3 ) de varias sesiones de roengenterapia profunda. Aquéllos y éstos los consideramos prácticamente curados, después de un período de observación y control radiográfico que aicanza a un máximo de 3 años 4 meses para el primero de nuestros casos. En el caso 3 , sometido a 12 aplicaciones de roengenterapia profunda, nos ha impresionado la intensa deformación y esclerosis del hueso ilíaco, provocada por las radiaciones, hecho que de acuerdo con nuestra limitada experiencia personal y por las opiniones recogidas en las di-

\section{CARACTERISTICAS CLINICAS FUUNDAMENTALES DE CUATRO CASOS DE GRANULOMA} EOSINOFLICO DE LOS HUESOS

\begin{tabular}{|c|c|c|c|c|c|c|c|c|}
\hline Caso & $\begin{array}{l}\text { Edad } \\
\text { (años) }\end{array}$ & $\begin{array}{l}\text { Iniciac. } \\
\text { enferm. } \\
\text { (dias) }\end{array}$ & $\begin{array}{l}\text { Sintomas } \\
\text { iniciales }\end{array}$ & $\begin{array}{l}\text { Locali- } \\
\text { zaclón }\end{array}$ & $\begin{array}{l}\text { Presunción } \\
\text { diagnóstica }\end{array}$ & $\begin{array}{l}\text { Osteollsis } \\
\text { radiográf. }\end{array}$ & $\begin{array}{c}\text { Easino- } \\
\text { filia } \\
/ /\end{array}$ & $\begin{array}{l}\text { Trata- } \\
\text { miento }\end{array}$ \\
\hline 1 & 13 & 60 & $\begin{array}{l}\text { Aumento de } \\
\text { volumen }\end{array}$ & $\begin{array}{l}\text { Parietal. } \\
\text { derecho }\end{array}$ & $\begin{array}{l}\text { Hundtmiento } \\
\text { cráneo? }\end{array}$ & Positiva & 13 & Raspaje \\
\hline 2 & 6 & 7 & $\begin{array}{l}\text { Dolor y } \\
\text { claudicación }\end{array}$ & $\begin{array}{l}\text { Cuello } \\
\text { fémur izq. }\end{array}$ & Sarcoma? & Positiva & 3 & $\begin{array}{l}\text { Raspaje } \\
\text { Roentge- } \\
\text { noterapia }\end{array}$ \\
\hline 3 & 4 & 28 & $\begin{array}{l}\text { Dolor y } \\
\text { claudicación }\end{array}$ & $\begin{array}{l}\text { Ala ilíaca } \\
\text { dererha }\end{array}$ & $\begin{array}{l}\text { Osteomie- } \\
\text { litis? }\end{array}$ & $\begin{array}{c}\text { Positiva } \\
\vdots\end{array}$ & 7 & $\begin{array}{l}\text { Raspaje } \\
\text { Radium } \\
\text { terapia }\end{array}$ \\
\hline 4 & 6 & 30 & $\begin{array}{l}\text { Aumento de } \\
\text { volumen }\end{array}$ & $\begin{array}{l}\text { Frontal } \\
\text { izquierdo }\end{array}$ & $\begin{array}{l}\text { Osteomie- } \\
\text { litis? }\end{array}$ & Positiva & 6 & Raspaje \\
\hline
\end{tabular}

servan en la perifería del foco osteolítico, lo cual, sumado a la escasez de "lipófagos", indicaba la relativa juventud del proceso y que correspondía, según los datos clinicos recogidos, a dos meses más o menos en los 3 primeros casos y alrededor de 1 mes en el último. Un carácter del proceso granulomatoso que nos llamó la atención fué el hallazgo frecuente de capilares y precapilares con acentuada proliferación de sus endotelias y fibrosis de sus delgadas paredes, que reducia ostensiblemente el lumen vascular, detalle histopatológico no consignado en la bibliografía consultada.

Respecto del tratamiento de nuestros casos, êste consistió en raspaje completo versas publicaciones consultadas, creemos puede y debe obviarse, reduciendo o tal vez suprimiendo la roengenterapia.

Creemos conveniente destacar que todos nuestros casos han correspondido a la forma solitaria del Granuloma eosinofílico, en aparente contradicción con la opinión más o menos generalizada de los autores que se han preocupado de estas materias, en el sentido de la frecuencia con que ellos han observado la forma plurifocal de esta afección. Respecto del pronóstico, éste ha sido muy favorable en todos nuestros casos y tenemos casi la convicción, después del tiempo que ha transcurrido desde el tratamien- 
to, que el simple raspaje puede constitujr la terapéutica suficiente $\mathrm{y}$ eficaz, evitándonos con ello las deformaciones del miembro afectado a que aludíamos más arriba, con lo que se acortaría también sensiblemente el tiempo de atención médica y hospitalización en enfermos.

Finalmente, nos resta agregar que estos cuatro casos de Granuloma eosinofílico han correspondido en su presentación a los últimos cuatro años, lo que significa una frecuencia relativa de un caso por año, hecho que nos hace pensar que en nuestro país puede existir esta enfermedad en una proporción muy superior a là que hasta ahora aparentemente tiene, asistiéndonos la creencia qué una revisión del material óseo operado o el examén histopatológico rutinario del producto de raspaje en los casos que comentamos, nos dará, a breve plazo, la frecuencia real entre nosotros de este discutido y más o menos raro cuadro anátomo-clínico.

\section{Resumen.}

Se relatan cuatro casos de Granuloma eosinofílico de los huesos, forma solitaria, en sus aspectos clínico, radiográfico y anátomo-patológico, precedido de un breve resumen bibliográfico sobre la materia.

Dos de nuestros casos correspondían a lesiones del cráneo, uno al cuello del fémur y el último del ala ilíaca. En todos ellos se practicó raspaje a cucharilla seguida en dos de ellos por roengenterapia. Todos los casos evolucionaron hacia la curación.

\section{Summary.}

The authors report four cases of eosinofilic granuloma of the bones, solitary type, and describe their clinical, radiographic and pathological aspects. Two of their cases corresponded to craneal lesions, another to the femur and the fourth to the iliac bone. In all of them corretagge was performed, followed in two by $\mathrm{X}$ ray therapy. All cases recovered.

\section{Bibliografía.}

BENGIOA, JOSE. - "Granuloma eosinófllo de los huesos". Bol. Hosp. Viña del Mar 1: 26, 1946.

BERANGER, R. y col. - "Granuloma eosinófilo múltiple en un lactante". Arch. Arg. de Pediatria XXXI: 198, 1949.

GREEN, W. and FARBER, S. - "Eosinophilic or Solitary Granuloma of Bone". Journal Bone and Joint. Srg. 499: 1942.

LARGHFERO I, PEDRO. - "Un caso de Granulcma eosinofílico de costilla" Anales Ortcp. y Trauma,t. 11; 115, 1949.

LICHTENSTEIN, L. and JAFFE, H. - "EOSInophilic Gramuloma of Bone". Aner. Jour. Path. XVI: $59 \overline{0}, 1040$.

MONTAGNE, A. y MORI-CHAVEZ, P. "Granuloma eosinofitico del femur". Bol. Acad. Peruana Cir. 11: 336, 1948.

OTANI and EHRLICH. - "Solitary granuloma of bone simulating primary neoplasm". Amer. Jour. Path. XVI: 479, 1940.

ORMSBY, O. and MONTGOMERY, H. - "EOsinophilic Granuloma of the Bone". Dis. of Skin. Phil. 1948.

PLATT, J. and EISENBERG, R. -- "Eosinophilic Granuloma of Bone". Jour. Bone. Joint. Surg. 761: 1948 .

PONSETTI, I. - 'Bone lesions in Eusinophilic Granuloma, Hans-Schüller-Christian Disease and Létterer-Siwe Disease". Jour. Bone Jolnt. Surg. 811: 1948 .

RAY BEVERLEY and col, - "Eosinophilic Granuloma of Bone". Jour, Bone Joint. Surg. 629: 1946.

SCHAJOWICZ, F' Y RETRACCI, L.- "A propósito de dos casos de granuloma histiocitario eosinófilo de hueso". Bol. y Trab. Soe. Arg. Ortop. y Traum. XVI: 86, 1951.

WEBE'R, L. y col. - "Granuloma eosinofílico del cuello del fémur". Bol. Trab. Soc. Arg. Ortop. y Traum. XVI: 106, 1951. 